\title{
Analysis of the factors affecting the mental health of students in Independent College
}

\author{
QI Yun-feng 1,, JIN Hai-yan1
}

(1. College of Binjiang ,Nanjing University of Information Science and Technology Nanjing, 210044, China)

qyf@nuist.edu.cn

\begin{abstract}
Keywords: Independent College Students; Mental Health; Affection Factors
\end{abstract}
\begin{abstract}
Use of mental health survey of university students in Nanjing five independent schools in the 1440 study of college students conducted a survey. The results showed that: Since the variables of age, gender, grade, professional types, should be successive, places of origin, whether the one-child, universities adapt to the situation, did not understand lectures, family income, family background, family relationships, whether living together harmoniously, the average monthly consumption, and social complex, loss of face reputation damage, different treatment, professional satisfaction, graduation certificate is different from learning difficulties etc 30 factors on the psychological impact on the situation, and these factors were categorized and analyzed.
\end{abstract}

\section{Introduction}

College students' mental health problem and the study of the method to solve these problems of education, has aroused widespread attention of colleges and universities nationwide. College students' psychological health education starts late in our country, has experienced a process from cognition to the value to strengthen. Since the $1990 \mathrm{~s}$, China began to attach great importance to the mental health education of college students, many experts and scholars on the subject in the research, put forward a lot of implementation method, education workers also on the method of mental health education for college students has made the beneficial attempt. The research and analysis of 5 independent college in nanjing city, 1440 college students as the research object, the effective sample for 1356.

This paper take research tool by the college students' mental health questionnaire is compiled by the basic situation of the questionnaire and symptom self-assessment scale (SCL - 90) in two parts (1). To prepare the basic situation of the questionnaire is in reference to the college students' mental health status in anhui province and its influence factor analysis and reading plenty of literature on the basis of the establishment. The self-assessment lists of symptom - SCL90 is one of the world's most famous mental health test scale, is the most widely used mental disorders and mental disease outpatient check scale.

\section{Research methods}

For all the data by using Excel and SPSS13.0 statistical analysis, and USES the T test and stepwise multiple regression method to analyze the data. One factor as the dependent variable (Y), of the factors involved in the self-made general questionnaire as independent variables, the multi-factor stepwise regression analysis, the results show that the independent variables such as school, such as age, gender, 30 influential factors on the psychological status. 


\section{Analysis and thinking}

\subsection{The social environment and the impact of evaluation on college students' mental health}

\subsubsection{The pluralistic values impact of independent college students psychological impact}

This research shows that: the complex has 690 people, often feel social sometimes feel there are 502 people, 164 people seldom feel; Have borne the brunt of pluralistic values, 1228 people, have been 128 people.

At present, our country is still in a period of social transition, inevitable meeting of the original system of social culture and morality to form a certain impact. Independent college students on the one hand, to adapt to college learning environment, living environment; On the other hand to contact with frequent changes in social life, the fierce social competition, the impact of commodity economy, they could produce psychological imbalance. At the same time, in the process of social transition, due to the market economic operation mechanism is not perfect, imperfect legal system, in recent years the society \"fake diplomal", ।"false certificatel" and so on, were severely corrupted society, to a certain extent, the erosion of independent college students' morality, independent college students' mental health.

\subsubsection{Discrimination to the influence of the independent college students mental health}

This research shows that: often feel be with normal college students have different treatment to 952 people, sometimes feel there are 98 people, 306 people seldom feel; Always feel unlike ordinary university graduation card, 76, 490 men often feel, sometimes feel there are 694 people, 96 people seldom feel.

In quite a number of people point of view, independent college students is \"underachiever〉" in the college entrance examination, and is generally ignored ।"third-class citizens\". This understanding deviation, make the independent college students' personality dignity severely damaged, independent college students in different occasions, different degree of inferiority, anxiety, depression, paranoid personality appeared from time to time. These make on their social competitiveness independent college students and the future is full of confusion, fear and uncertainty, resulting in considerable psychological pressure, the independent college students are prone to mood, such as depression, paranoia, hostility to society and other people's evaluation to the extreme and one-sided, or even a serious disciplinary violations, etc.

\subsection{The effect of school for independent college students mental health}

\subsubsection{School type, grade of the influence of the independent college students mental health}

The survey of jinling institute, 280, 288, north college kangda college 228, zijin college, 284, binjiang institute of 276 people, it is found that psychological obstacle detection rate: jinling, binjiang, zijin college students is higher than north, kangda college students. This may be related to north central college and kangda college associated with mental health education curriculum.

This study reveal that nanjing grade two or three independent college students' psychological health level is higher, a and grade four college students' psychological health level is lower, the student's university adaptation, learning pressure and severe employment pressures are inseparable. Tsinghua university's investigation showed that personal prospects and employment has become one of the most important factors in the college students' psychological pressure, and pressure tends to rise with higher grade [2]. 


\subsubsection{For independent college students mental health professional}

Investigation shows that: science, engineering and business students psychological detection rate is higher than the other, liberal arts, medical students, and in addition to the liberal arts and business, arts and medical, science and engineering, engineering and medical, business and no significant difference between medical, other differences between multiple factors significantly.

According to a survey of 72 students are not satisfied with their majors, accounting for $5 \%$ of investigation number, 606 students for the professional satisfaction for general, accounting for $45 \%$ of investigation number, and your are not satisfied with your major students SCL - 90 score significantly higher than satisfied with the professional students. This result is consistent with the existing research conclusion [4]. Professional degree of satisfaction is an important influencing factor of the mental health status. Study found that as the satisfaction of professional gradually reduce, the freshmen in the various factors on the higher the score, the possibility of corresponding psychological problems.

\subsubsection{The study on the influence of the independent college students mental health}

On the surface, to the independent college students learn, no entrance pressure, study time and the content is more freedom, by learning the psychological stress should be reduced. But in fact, due to changes in university learning strategies and learning methods, combined with a variety of comprehensive examination, such as English and computer grade examination and the pressure of employment competition, university level study pressure increasing, the results of the survey found that 1028 college students often and always don't understand, accounted for $76 \%$ of investigation number; 716 people feel learning difficulties, accounted for 53\% of investigation number; 232 students had make-up examination or rebuilt, accounting for $17 \%$ of the survey number. Because of these invisible pressure, can make the students have a series of psychological problems, including learning disabilities, are not interested in your major, test anxiety, learning motivation, learning orientation, learning the experience of impotence, such as inferiority [5].

\subsubsection{Employment for independent college students mental health}

The survey results show that worry to worry about the job or student 958 people, accounting for $71 \%$ of the survey number.

Competition in the employment environment for college students has brought large psychological pressure, main show is as follows: excessive anxiety and impatience, passivity and ।"unsuccessful\" psychological, blind confidence, roll at comparison with envy and resentment psychology and behavior, physiological disorders and so on.

\subsubsection{Psychological guidance to the influence of the independent college students mental health}

Any item 3 meter or 10 symptoms factor for more than mild or moderate mental disorders; Any item 2 or more are prone to psychological barriers or mild mental disorder. Can be seen from table 1 , the number of students in more than mild or moderate mental disorder to 104, accounting for $7.67 \%$ of the total; Students with mild mental disorder to 194 people, accounting for $14.31 \%$ of the total; Nanjing whether the independent college school lectures on psychological counseling, psychological influence college students' psychological obstacle detection rate, the number of schools often rarely conduct psychological lectures is 236, of which more than mild or moderate psychological barriers for the number of 16 people, accounting for $4.26 \%$ of the total. Had mild psychological barriers for the number of 94 people, accounting for $47 \%$ of the total; The number of 
schools have no psychological lectures is 96, among them more than mild or moderate psychological barriers of 8 people, the number of accounts for $8.33 \%$ of the total. Had mild psychological barriers for the number of 28 people, accounting for $29.17 \%$ of the total; From that school whether to carry out psychological counseling, psychological lecture to a large extent affect the mental health status of the independent college students.

Table 1 In nanjing, the independent college students factors related to the psychological counseling

\begin{tabular}{|c|c|c|c|c|c|c|c|c|}
\hline \multirow{2}{*}{$\begin{array}{c}\text { All kinds of } \\
\text { samples } \\
\text { (number) }\end{array}$} & \multicolumn{2}{|c|}{\begin{tabular}{c} 
the factor points \\
\cline { 2 - 9 }
\end{tabular}} & \multicolumn{2}{|c|}{$\begin{array}{c}\text { the factor points } \\
\mathrm{n}\end{array}$} & \multicolumn{2}{|c|}{$\begin{array}{c}2 \leqslant \text { the factor } \\
\text { points }<3\end{array}$} & \multicolumn{2}{c|}{$\begin{array}{c}1 \leqslant \text { the factor } \\
\text { points }<2\end{array}$} \\
\hline $\begin{array}{c}\text { The total } \\
\text { number (678) }\end{array}$ & 104 & $7.67 \%$ & 298 & $21.98 \%$ & 194 & $14.31 \%$ & 1058 & $78.02 \%$ \\
\hline Often (110) & 6 & $2.7 \%$ & 6 & $2.7 \%$ & 0 & $0 \%$ & 214 & $97.27 \%$ \\
\hline $\begin{array}{c}\text { Sometimes } \\
\text { (332) }\end{array}$ & 74 & $11.14 \%$ & 146 & $21.99 \%$ & 72 & $10.84 \%$ & 518 & $78.01 \%$ \\
\hline Rarely (188) & 16 & $4.26 \%$ & 110 & $29.25 \%$ & 94 & $25 \%$ & 266 & $70.74 \%$ \\
\hline No (48) & 8 & $8.33 \%$ & 36 & $37.5 \%$ & 28 & $29.17 \%$ & 60 & $62.5 \%$ \\
\hline
\end{tabular}

\subsection{The family influence on independent college students mental health}

\subsubsection{Family situation on the influence of the independent college students mental health}

Survey results show that college students from cities and towns of SCL - 90 score significantly lower than the college students from countryside, mental health is better than that of students from the rural areas. College students from countryside, face the greatest difficulty is the family economy, the survey showed that the annual family income of less than 10000 yuan of students has 182, accounts for $13.42 \%$ of investigation number, annual income is in 10000 yuan - 20000 yuan student 338 people, accounting for $24.93 \%$ of investigation number, and scL - 90 score significantly higher than the annual household income in 40000 yuan of above. Family economic income is lower, the students' psychological health level is lower, show more symptoms, interpersonal sensitivity, low self-esteem, depression, depressed and psychotic bad mood and behavior. Therefore, family background and family economic impact on college students' mental health is obvious.

\subsubsection{One-child influence on independent college students mental health}

The survey results show that the survey of 1002 independent colleges in nanjing the only-child college students each factor points are lower than the only-child college students, to explain the mental health status is better than that of the only-child college students, and somatization, force, interpersonal relationship, depression, anxiety, hostility, terror, paranoia, psychosis, other 10 symptoms factor $(\mathrm{p}<0.001)$ differences are significant. This conclusion to those findings consistent with domestic [6], the one-child mental health is better than not only children, this may be related to the one-child family growth environment, good parenting, family relationship and loose family economic conditions, their family there is advantage in many ways, so that they have a lively and cheerful, optimistic and generous, self-confidence, reasonable disposition.

\subsubsection{Family structure, the influence of the relationship of independent college students mental health}

Scholars study suggests: the bad family environment influence on mental health is more serious, bad family environment mainly includes the relationship between parents and family members have long illness and so on many factors [7]. The survey shows that: family relationship apathy has 16 
people, accounting for $1.18 \%$ of investigation number, various factors are higher than students family relationship harmony, explain the mental health status is lower than the harmony of college students and family relations.

At present in colleges and universities, single-parent children are in the minority. According to the survey, children of single-parent families typically $1 \%$ of the total number of students - 3\%, however, single parent families children's mental health problem is quite serious, to have a serious mental health problems of more than $60 \%$ of the students. Mainly for the following several aspects: (1) the cold, is lonely and reluctant to communication; (2) the pessimistic inferiority, lack of enterprising spirit; (3) personality quirks, easy to do STH unconventional or unorthodox, strong rebellious attitude [8]. Students with special background of family structure, easy to form withdrawn, inferiority, paranoid, extreme dark psychological, is the high-risk groups of college students psychological problems [9].

\section{Conclusion}

Age, gender, 3.1 should all previous to the influence of the independent college students mental health

The survey of the independent college of nanjing university students aged between 17 and 24 span, and as the growth of the age and negatively correlated to the independent college students mental health status, it may has a lot to do with graduation and employment.

The survey shows that nanjing of independent college students mental health status of both men and women differ, girls 10 symptoms factor were higher than boys, boys showed a higher level of mental health, somatization, interpersonal relationship, depression, terror $(\mathrm{p}<0.001)$; Other $(\mathrm{P}<$ $0.01)$ and force, anxiety, hostility, psychoticism $(\mathrm{P}<0.05)$ has a significant factor differences. Boys in the paranoid symptoms factor score lower than girls, but close to, does not have significant difference. The survey showed that each factor points are lower than the previous college students graduate, explain the mental health status is better than the previous college students.

\subsection{At the university of life events on the influence of the independent college students mental health}

University life events are the important factors that affect college students' mental health, affect college students' mental health level of the variable is the university to adapt to the situation, whether to get along, the average monthly consumption, face and reputation, frightened, physical exercise.

No discrimination in life, is frightened, will naturally cause psychological changes greatly. Such as encountered some face thing, always feel lift head, easy to cause psychological pressure and mental highly nervous, resulting in a low self-esteem. Physical exercise will significantly influence the mental health of college students. Because sports has its unique content and form, can eliminate tension, promote self-awareness and self-control, inspire initiative and encourage college students to excel and the pursuit of healthy and positive life goal, finally help students improve the level of mental health [10].

\subsection{The love to the influence of the independent college students mental health}

College students' psychological characteristics summarized as: love pay attention to the love process, despised love results; Subjective education first, the supremacy of objective love; Love, open and down traditional morality; Lovelorn tolerant attitude, to bear ability is weak [11]. Love, love, unrequited love had a great influence on the students' mental health, especially in love after a 
setback, a lot of college students appeared out of control and abnormal psychology, produce extreme sense of loneliness, despair and void, and generally characterized by low self-esteem, despair, revenge, indignation and depression.

\section{References}

[1] Wang Xiangdong,Wang Xilin,Ma Hong. The mental health scale [J].Chinese Mental Health Journal,1999,12(2):31-35.

[2] Zhang Weiping,Yang Xiaolin. Study on influence of Aerobics on the mental health of College Students[J]. Chinese Journal of school health,1999,20(2):104-106.

[3]Ttian Jiali,Xu Guangyu,Peng Xiukun. The Independent Institute of mental health of college students and the influencing factors[J]. Chinese Journal of health psychology,2005,(4):316-318.

[4]Sun Jianhua. Analysis of the mental health status of Freshmen in Independent Colleges and professional satisfaction [J]. Journal of Anhui University Of Science And Technology, 2007,9:80-83.

[5] Wang Xiting. The psychological health education of College Students[M]. East China Normal University press,2004.6:77-80.

[6] Duan Xingxing,Chi Zhongjun,Zhang Lixian. An investigation on the mental health of the only child college students.[J]. Youth Study,1997,2:17-21.

[7]Yang Tai. Study on the influence of family environment on mental health of College Students[J]. Journal of Qiqihar Medical School,2001,22(6):677-678.

[8] Wang Fengdong,Zhang Huiqin. Children from single parent family's personality, behavior and education [J]. Journal of North China Institute of Technology,2003,19(2):32-33.

[9] Zhang Maoyun,He Guangwei,Liu Qiong. Influence of family structure on the mental health of College Students [J]. Journal of First Military Medical University,2004,27(2):159-161. 